Available online at www.sciencedirect.com

\title{
In Vivo and in Vitro Evidence that the Four Essential Intermediate Filament (IF) Proteins A1, A2, A3 and B1 of the Nematode Caenorhabditis elegans Form an Obligate Heteropolymeric IF System
}

\author{
Anton Karabinos ${ }^{1}$, Ekkehard Schulze ${ }^{2}$, Jürgen Schünemann' \\ David A. D. Parry ${ }^{3}$ and Klaus Weber ${ }^{1 *}$
}

${ }^{1}$ Max Planck Institute for Biophysical Chemistry

Department of Biochemistry

Am Fassberg 11, 37077

Goettingen, Germany

${ }^{2}$ Third Department of

Zoology-Developmental

Biology, University of

Goettingen, Humboldtalle $34 \mathrm{~A}$

37073 Goettingen, Germany

${ }^{3}$ Institute of Fundamental

Sciences, Massey University

Palmerston North, Palmerston

New Zealand

\begin{abstract}
The in vitro polymerization and tissue-specific expression patterns of the four essential intermediate filament (IF) proteins (A1, A2, A3, B1) and the non-essential IF protein A4 were analyzed. Recombinant B1, used as a probe in blot overlay assays of the 11 Caenorhabditis elegans IF proteins, reacted strongly with proteins A1 to A4, indicating a heterotypic interaction. Obligate heteropolymeric filament assembly in vitro was confirmed by electron microscopy. Protein B1 formed long IF when mixed with an equimolar amount of A1, A2 or A3. Developmentally regulated coexpression of B1 and one or more members of the A family was found with GFP-promoter reporters. This coexpression pattern argues for a heteropolymer system in vivo. One or both splice variants of the B1 gene are always coexpressed in a tissue-specific manner with at least one member of the A family in hypodermis, pharynx, pharyngeal-intestinal valve, excretory cells, uterus, vulva and rectum. Interestingly, while the intestine normally lacks a B1/A pair, the dauer larva shows intestinal B1 and A4. These results are in line with similar postembryonic phenotypes of the hypodermis induced by RNA interference (RNAi) of genes B1, A2 and A3. Similarly, defects of the pharynx and its A1-GFP containing tonofilaments observed in the postembryonic B1 RNAi phenotype are consistent with the coexpression of B1 and A1 in the marginal cells. Thus RNAi analyses provide independent evidence for the existence of the B1/A obligate heteropolymer system in vivo. Proteins A1 and B1 have a similar and rather slow turnover rate in photobleaching experiments of the pharynx tonofilaments.
\end{abstract}

(C) 2003 Published by Elsevier Ltd.

Keywords: C. elegans; intermediate filament; heteropolymers; RNA interference; paralysis

\section{Introduction}

Intermediate filament (IF) proteins are important components of the cytoskeleton in many metazoa. Man has more than 65 different IF genes. ${ }^{1}$ All IF proteins show a common tripartite structure. Variable head and tail domains flank the central $\alpha$-heli-

Abbreviations used: dsRNA, double-stranded RNA; FRAP, fluorescence recovery after photobleaching; GFP, green fluorescent protein; IF, intermediate filament; RNAi, RNA interference.

E-mail address of the corresponding author: office.weber@mpibpc.gwdg.de cal rod domain, which can form a parallel doublestranded coiled coil. On the basis of sequence similarities, biochemical properties, tissue-specific expression patterns and the organization of the corresponding genes, five major subfamilies are identified. Human type I and II proteins are, with 25 members each, by far the largest subfamilies. They encode the keratins I and II, which give rise via a hetero coiled coil to the obligate heteropolymeric keratin filaments of epithelia and epidermal appendages. The four type III proteins can form, at least in part, homopolymeric IF. The seven genes coding for type IV proteins show a unique intron pattern totally unrelated to that of type I to 
III genes. Finally, type $\mathrm{V}$ covers the nuclear lamins. $^{2-4}$

Point mutations in many IF genes are connected to human diseases. Mutations in at least 14 epidermal keratin genes cause various fragility syndromes of the skin, ${ }^{5}$ and indicate that one function of IF is connected with cellular resistance to mechanical stress. Similar mutations in the type III genes desmin and GFAP are associated with myopathies and Alexander's disease, respectively., Ablation of murine genes gives sometimes corresponding results but often only mild phenotypes are observed. ${ }^{8}$

There are two prototype sequences of cytoplasmic IF proteins that parallel metazoan phylogeny. Compared with nuclear lamins, the first prototype, originally defined in the vertebrates, lacks 42 residues (six heptads) in the coil $1 \mathrm{~b}$ subdomain of the central rod. It accounts for the currently known 13 sequences of the cephalochordate Branchiostom $a^{9}$ and the five sequences of the urochordate Ciona. ${ }^{10,11}$ The early chordates have orthologs of type I to III proteins and some IF proteins without an obvious vertebrate counterpart. Neurofilament type IV proteins emerged only with the vertebrate lineage. Thus, the first sequence prototype is specific for the chordates.

The second prototype of cytoplasmic IF proteins covers all sequences established from 12 different protostomic phyla. ${ }^{12,13}$ Here, the coil $1 \mathrm{~b}$ subdomain has always the same length as in nuclear lamins and the tail domain displays often a lamin homology segment. The nematode C. elegans has a single nuclear lamin, which is an essential protein of the early embryo, ${ }^{14,15}$ and 11 genes encoding cytoplasmic IF proteins. Using RNA interference (RNAi) with microinjected double-stranded RNA (dsRNA) on all 11 genes, we identified four genes essential for nematode development (A1, A2, A3 and B1) and a mild adult phenotype for one gene (C2) ${ }^{16}$ The phenotypes for the IF proteins A2 and A3 indicate an essential role of the hypodermal IF in the transmission of muscle force to the cuticle and the maintenance of the correct hypodermis/ muscle relationship in development. ${ }^{17-20}$

Using GFP-promoter reporters, we have analyzed the expression pattern of the four essential IF genes as well as of the A4 gene during C. elegans development. A strict coexpression of B1 and at least one member of the A1 to A4 group is observed. This coexpression pattern relates to the in vitro polymerization properties of the proteins. In gel overlays of all 11 recombinant IF proteins, B1 strongly decorates only A1 to A4, while filament assembly studies show that $\mathrm{B} 1$ gives rise to obligate heteropolymeric IF when mixed with equal molar amounts of A1, A2 or A3. Using B1 RNAi by feeding ${ }^{21}$ on wild-type as well as on transgenic worms expressing the A1-GFP protein we observed a postembryonic phenotype similar to that found earlier for A2 and A3. This result fits the hypodermal coexpression of $\mathrm{B} 1$ with $\mathrm{A} 2$ and A3. The postembryonic B1 RNAi phenotype obtained by feeding shows additional defects of the A1-GFP-containing tonofilament bundles in marginal cells in line with the coexpression of B1 and A1 in the pharynx.

\section{Results \\ Expression patterns of $\mathrm{A} 1 \mathrm{a}, \mathrm{B} 1 \mathrm{a}$ and $\mathrm{A} 4$ promoter/gfp reporters}

The four genes A1 to A4 and the two genes B1 and $\mathrm{B} 2$ form the $\mathrm{A}$ and $\mathrm{B}$ protein subgroups in the collection of the 11 C. elegans IF proteins (Figure $1 \mathrm{~A}$ and $\mathrm{B}){ }^{16}$ In addition, the $\mathrm{A} 1$ and the $\mathrm{B} 1$ genes each produce two alternative splice variants designated A1a, A1b and B1a, B1b (Figure 1A). ${ }^{16,22}$ The protein A1b (F38B2.1a) differs from the shorter splice variant A1a (F38B2.1b) by an additional 25 residues on the $\mathrm{N}$-terminal end that are encoded by the separate A1b-specific exon (Figure 1C). Similarly, the different $\mathrm{N}$ termini of the B1a (F10C1.2a) and B1b (F10C1.2b) proteins are encoded by the two distinct B1a and B1b-specific exons (Figure 1C). Expression patterns of A1b, A2 (W10G6.3), A3 (F52E10.5) and B1b have been reported. ${ }^{16,20}$ To complete the expression analysis of the four essential IF genes $\mathrm{A} 1$ to $\mathrm{A} 3$ and $\mathrm{B} 1^{16}$ we determined the expression patterns of the A1a and B1a genes and added also the A4 (K05B2.3) gene.

Inspection of the genomic sequence containing the entire A1 gene (F38B2.1) indicated that the $1946 \mathrm{nt}$ genomic sequence located between the A1b-specific exon and the rest of the gene could act as an A1a-specific promoter (Figure 1C). We therefore amplified this sequence together with the following A1 gene by PCR, fused the sequence to gfp of the pEGFP-N1 plasmid and used this construct to prepare the non-integrated transgenic lines. The resulting promoter-driven A1a/GFP expression was monitored in the C.elegans strain DP38 unc-119(ed3) III rescued for unc-119 (for details, see Materials and Methods). As shown in Figure 2, A1a/GFP was expressed and integrated into the thick filament bundles of the pharynx, the excretory cell, the vulva and the rectum of the larva. The strong expression in the pharynx was visible already in late embryos (data not shown). In adults, an additional GFP-containing network was found in the uterus (Figure 2I).

A similar strategy was used to determine the expression pattern of the B1a gene in wild-type worms. The $3186 \mathrm{nt}$ fragment, immediately upstream of the B1a-specific exon (Figure 1C), was fused to gfp and used to prepare the non-integrated transgenic line. The Bla promoter/gfp reporter was strongly expressed in the embryonic and the early larval hypodermis (Figure 3A). Additional expression was seen in cells associated with the amphid sensory neurons, the excretory cells, the vulva, the nerve cord and the rectum, as well as in some neurons of the tail of the late larva or the 
A
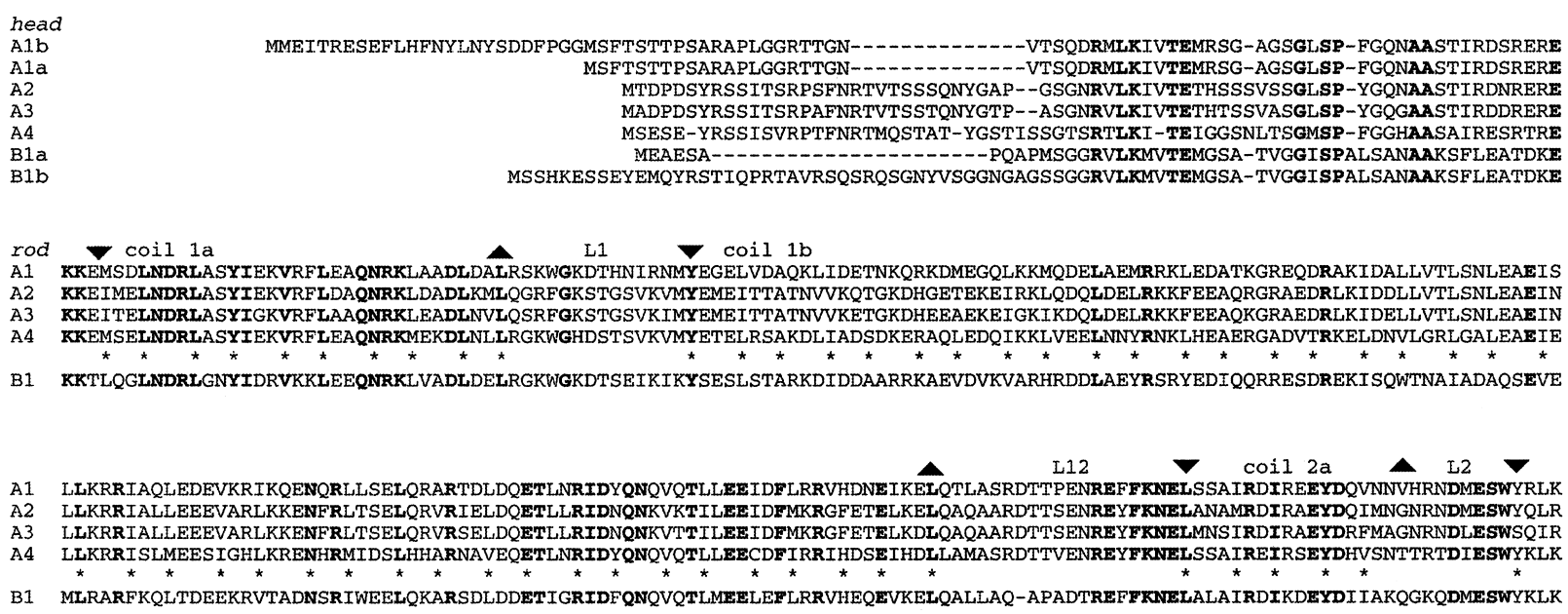

stutter
A1 VQII $2 b$ VQEINTOSNRQNAENNYQKEEVKRLRNQTSELROKLSDLESRNLLLEKOIEDLNYQLEDDQRSYEAALNDKDAQIRKLREECQALMVELQMLLDTKQTLDGELKVYRQMLEGNSEGM

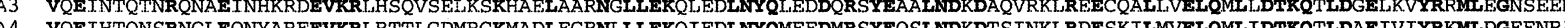
VQEIHTQNSRNCLEQNYAREEVKRLRTTLGDMRGKMADLEGRNLLLEKQIEDLNYQMEEDMRSYEQSLNDKDTSINKLRDESKILMVELQMLIDTKQTLDAEIVIYRKMLDGEENRA VSEVOGSANRANMESTYORDEVKRMRDNIGDLRGKLGDLENKNSLLEKEVONLNYOLTDDOROYEAALNDRDATLRRMREECOTLVAELOALLDTKOMLDAEIAI YRKMLEGEETRV

$\operatorname{tai}$

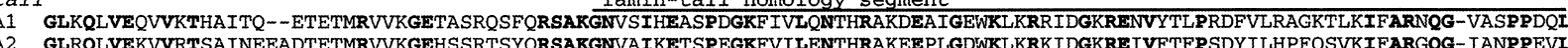
A3 GLROLVEKVVRTSA INEEVDTETMRVVKGEHSSRTSYORSAKGNVSIKEVSPEGKFVILENTHRAKEEPLGDWKLKRKIDGKREIVFTFPSDYILHPFQSVKIFARGQG-IANPPEVI A4 GLRQLVEOVVKTTSIHOTKEIESLRVLKGETTSHSSYSRSAKGNIAIOEAEPSGKYIVLENISR-RDENIGDWKLRRKIAGKRETVFTFPREFTLRAOKSVKIFARGOG-VHSPPDSI B1 GLTQMVEOAVKTHSLQQQENTDSTRSVRGEVSTKTTTFORSAKGNVTISECDPNGKFIKLENSHRNKDENVGEHKTRRKLDGRREIVYSTPANVVIKPGKNLTIIYARDOGGINNPPESI

A1 VYDAEDSFGSGNNVQTILFNKEGEERATHIQROSTA

A2 IFEGDETFGVGANVQTILYNNKGEERATHIQRQSQQTTSS

A3 VFEGDDTFGAGANVTILYNNSGEERATHMQRQSQQTTTS

A4 VYDLEDSFGTGNDVVTTLYMKEGEDRASHSQRASHT

B1 VFDGENTWGIGANVVTSLVNKDGEERATHTQKTIQSGQ

B

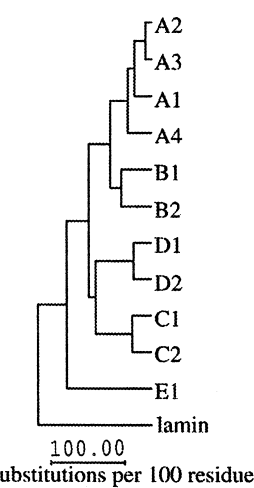

C
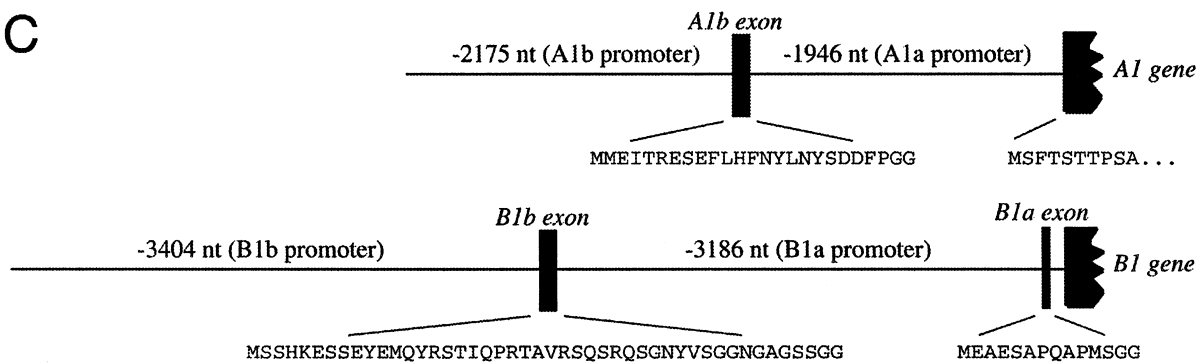

$1000 \mathrm{nt}$
$2419 \mathrm{nt}$ (A4 promoter)

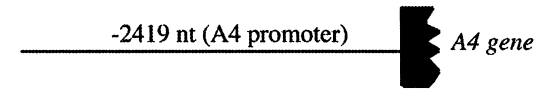

Figure 1. A, Comparison of the amino acid sequences of the C. elegans IF proteins A1a, A1b, A2, A3, A4, B1a and B1b. The typical IF domain organization consisting of head, rod and tail domains is indicated. Arrowheads pointing down or up mark the start and end of the four rod subdomains (coil 1a, 1b, 2a, 2b) which are connected by three non-helical linkers (L1, L12, L2). Asterisks (*) given in the lines between the A1 to A4 and B1 rod sequences mark $a$ and $d$ positions of the heptad repeat pattern with the stutter in coil $2 \mathrm{~b}$ (details of IF structure have been published ${ }^{2-4,27}$ ). Dashes optimize the sequence alignment. Bold letters indicate amino acid residues that are identical in all sequences. B, Evolutionary tree formed by the rod domains of the 11 cytoplasmic IF proteins and the single nuclear lamin of C. elegans. The tree was constructed using the unweighted pair-group method with arithmetic mean (UPGMA). $\mathrm{C}$, Diagrams of the genomic sequences containing the A1, B1 and A4 genes. In the diagram of the A1 gene the $1946 \mathrm{nt}$ genomic sequence located between the A1b-specific exon and the rest of the A1 gene was used as promoter for the A1a promoter/gene/gfp construct (see Figure 2 and Results). The genomic sequence upstream of the A1b exon was used previously for the A1b promoter/gfp reporter.$^{16}$ In the B1 gene diagram, the 3186 nt genomic sequence located between the B1b and B1a-specific exons was used as promoter in the B1a promoter/gfp construct (see Figure 3 and Results). The genomic sequence upstream of the B1b exon was used previously in the B1b promoter/gfp reporter ${ }^{16}$ and here to drive the expression of the B1a cDNA in transgenic worms analyzed by FRAP (for details, see the text). The genomic sequence of 2419 nt upstream of the A4 gene was used in the A4 promoter/gfp construct (see Figure 3 and Results). The unique N-terminal amino acid sequences of proteins A1b, B1a and B1b (see A), all encoded by separated exons, and of protein A1a are given. 


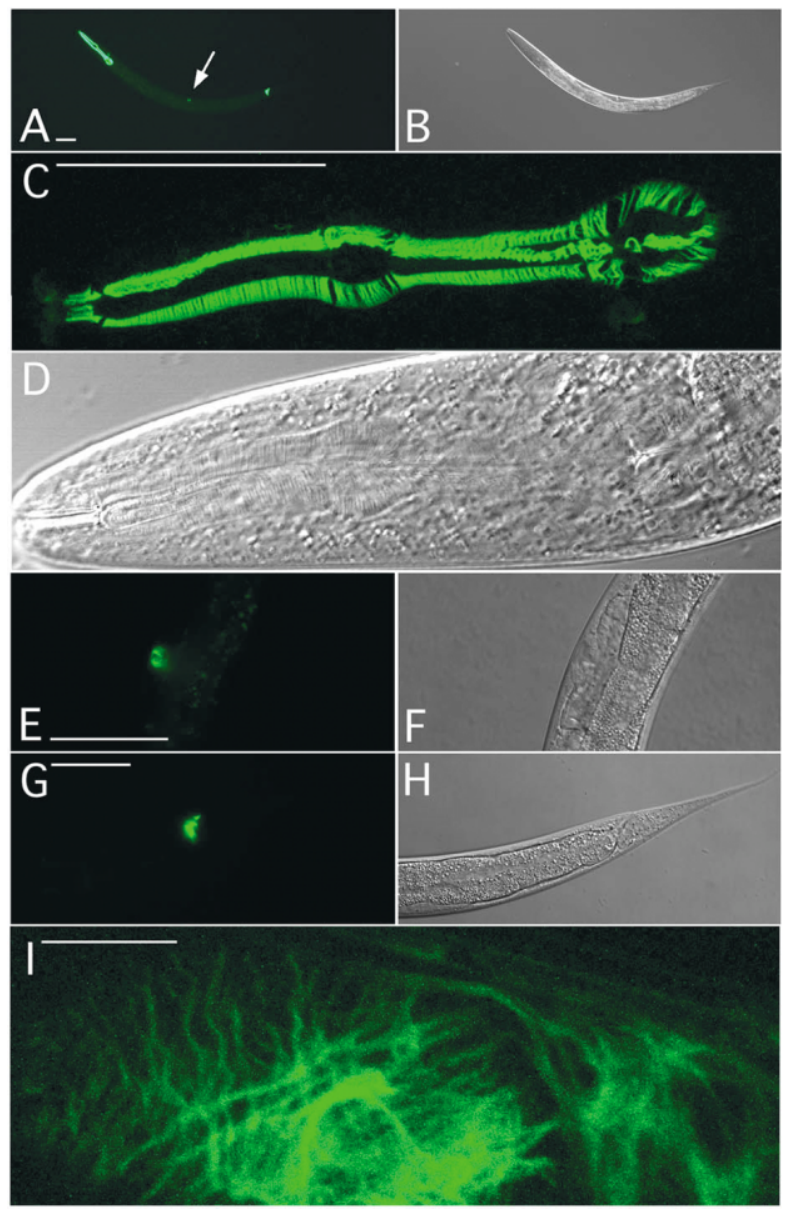

Figure 2. Tissue-specific expression of the A1a-promoter/gene/gfp construct in larva and adult. The $1946 \mathrm{nt}$ 5'-upstream region plus the entire A1 gene (see Figure 1B, and Materials and Methods) were used in the A1a-promoter/gene/gfp reporter. Nomarski phase contrast monitoring ( $\mathrm{B}, \mathrm{D}, \mathrm{F}$ and $\mathrm{H}$ ) was used to facilitate the identification of cells and tissues. In the larva, expression of the A1a-GFP was detected in the filament bundles of the pharyngeal marginal cells, the rectum and the vulva (the latter marked by the arrow in A). C, $E$ and $G$ Higher magnifications of the pharynx, vulva and rectum of the larva given in A. In addition, strong A1a-GFP-fluorescent filament bundles were present in the uterus of the adult (I). Scale bars represent $25 \mu \mathrm{m}$.

juvenile (marked with arrows in Figures 3B-D). A similar expression pattern was detected in adults, which, however, lacked the hypodermal expression (marked with arrowheads in Figure 3C and D) seen at earlier developmental stages.

Expression of the A4 gene in wild-type worms was determined using the promoter/gfp reporter containing the $2416 \mathrm{nt}$ genomic sequence directly upstream of the A4 coding sequence (Figure 1C) This construct was detected in the larva in the pharyngeal-intestinal valve, the rectum and some neurons of the tail (Figure 3E). In the adult (Figure 3F-H) additional expression was seen in the excretory cells and in some unidentified cells in the middle of the body (marked by the arrow in
Figure 3G). Interestingly, the A4 promoter/gfp reporter was strongly up-regulated in the intestine of the newly formed dauer larva (Figure 3I and J), while the intestine of the normal developmental stages lacks A4 expression.

The strong hypodermal expression of the B1a promoter/gfp reporter described above differs from our previous immunostaining results using a rabbit anti-B1 specific antibody that did not significantly stain the hypodermis. ${ }^{16}$ However, new experiments in which the antibody was used at higher concentrations (see Materials and Methods) clearly decorated the hypodermis. This staining pattern gradually evolved from patches seen in the embryo (Figure 4A, C and E) into a stripe pattern in the larvae (Figure $4 \mathrm{G}$ ) and in adults (not shown). In agreement with our previous results, ${ }^{16}$ this staining pattern is very similar to that obtained with the monoclonal antibody $\mathrm{MH} 4$ (for details, see Figure 4B, D, F and H; and see Francis \& Waterston ${ }^{17}$ and Hresko et al. $\left.{ }^{18}\right)$ ), which reacts strongly with recombinant IF proteins A1, A2 and A3 in immunoblots. ${ }^{16}$

Table 1 summarizes the results on the GFPpromoter expression of genes A1a, B1a and A4 as well as results obtained previously with GFPpromoters of genes A1b, A2, A3 and B1b. ${ }^{16,20}$ The combined results show that one or both splice variants of the B1 gene are tissue-specifically and developmentally coexpressed with at least one member of the A gene family in the hypodermis, the cells associated with the amphid sensory neurons, the pharynx, the pharyngeal-intestinal valve, the excretory cells, the uterus, the vulva and the rectum. Interestingly, the intestine of the dauer larva shows strong coexpression of the A4 and $\mathrm{B} 1 \mathrm{~b}$ genes, although normally the intestine lacks expression of these genes. Here, we note that some tissues, such as the pharyngeal and the body muscles, do not express proteins B1 and A.

\section{Biotinylated B1 binds A1, A2, A3 and A4 strongly in blot overlay assays}

The coexpression of the B1 and the A proteins described above raised the question of whether these IF proteins form heteropolymeric filaments or separate homopolymeric filaments in nematode cells. To answer this question, the recombinant protein B1a was labelled with biotin and used as a probe to investigate its binding to all 11 recombinant nematode IF proteins (A1b, A2 to A4, B1a, B2 (F10C1.7), C1 (F37B4.2), C2 (M6.1), D1 (R04E5.10), D2 (F25E2.4) and E1 (C43C3.1) in blot overlays (see Materials and Methods). Figure 5 shows that the biotinylated $\mathrm{B} 1 \mathrm{a}$ recognizes proteins $\mathrm{A} 1 \mathrm{~b}, \mathrm{~A} 2$, A3 and A4 strongly, while a very much weaker binding was detected on C2 and E1. No homotypic B1/B1 interaction was observed. These results suggest that protein B1 may form heteropolymeric filaments with the four IF proteins A1 to A4, which comprise the largest subgroup of C.elegans IF proteins (Figure 1B). ${ }^{16}$ 


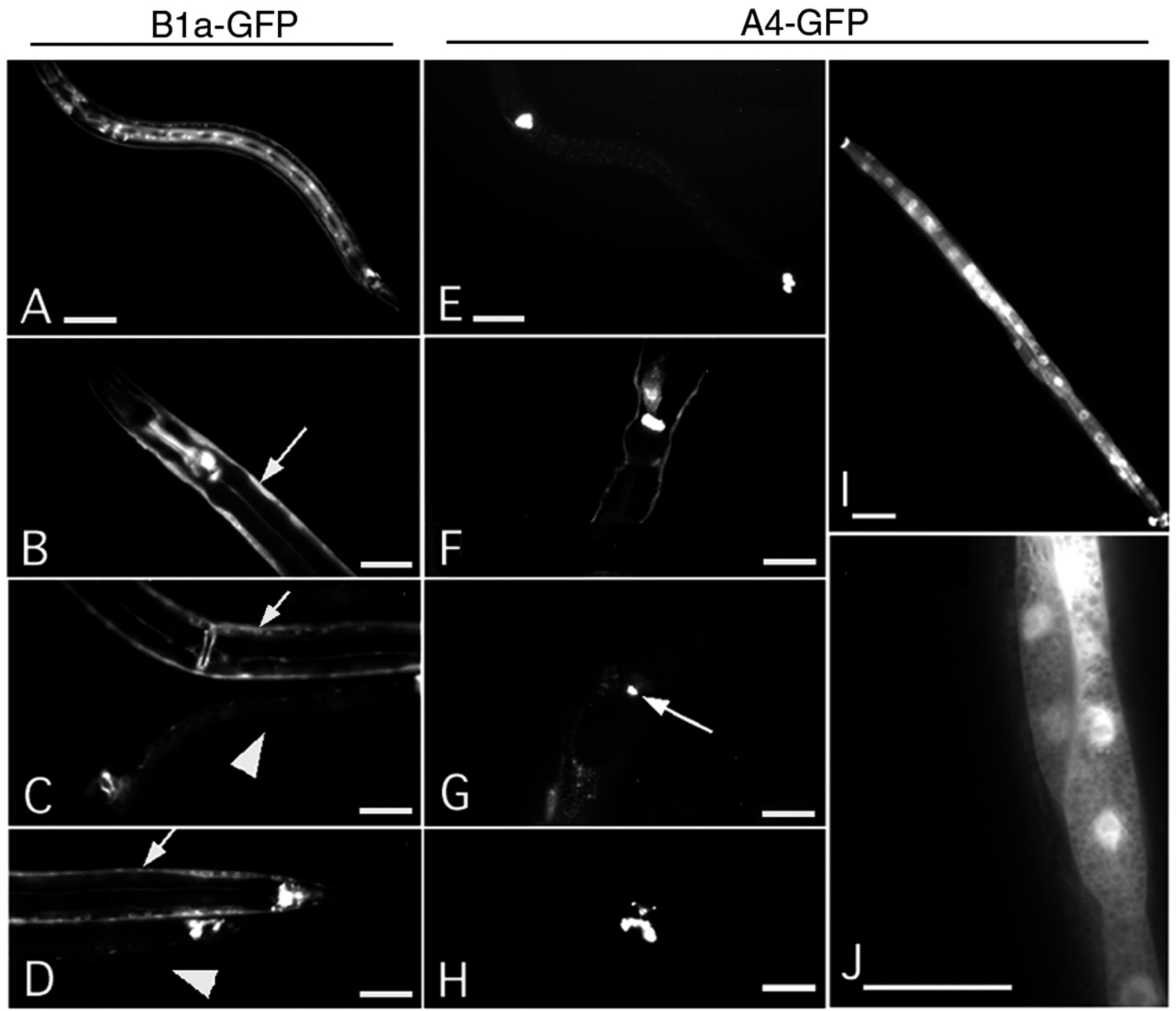

Figure 3. Tissue-specific expression of the B1a and A4-promoter/gfp constructs in larva and adult. Expression of the B1a-promoter driven GFP in the larva was detected in the main body hypodermis (excluding the seam cells), the pharynx, the excretory cells and the rectum (A). This expression pattern and the additional expression in the vulva were seen in the late larva/juvenile (marked by arrows in B-D), while no signals were detected in the adult hypodermis (marked by arrowheads in C and D). Expression of the A4-promoter driven GFP in larva was detected in the pharyngeal-intestinal valve and the rectum (E). This and the additional staining in the H-shaped excretory cells $(\mathrm{F}$ and $\mathrm{H})$ and some other unidentified interior cells $(\mathrm{G})$ were seen in the adult. The A4-promoter/gfp construct was upregulated strongly in the newly formed dauer larva (I and its higher magnification in J). Scale bars represent $50 \mu \mathrm{m}$ for $\mathrm{A}-\mathrm{H}$ and $25 \mu \mathrm{m}$ for I and $\mathrm{J}$.

Table 1. Tissue specific coexpression of proteins A1 to A4 with B1 monitored by GFP-promoter reporters

\begin{tabular}{|c|c|c|c|c|c|c|c|c|c|}
\hline $\begin{array}{l}\text { IF pro- } \\
\text { tein }\end{array}$ & Hypodermis & $\begin{array}{l}\text { Cells of the } \\
\text { amphid }\end{array}$ & Pharynx & $\begin{array}{l}\text { Pharyngeal-intesti- } \\
\text { nal valve }\end{array}$ & $\begin{array}{l}\text { Excretory } \\
\text { cells }\end{array}$ & $\begin{array}{l}\text { Intestine of } \\
\text { dauer larva }\end{array}$ & Vulva & Uterus & Rectum \\
\hline A1a & - & - & + & - & + & - & + & + & + \\
\hline $\mathrm{A} 1 \mathrm{~b}$ & - & + & - & + & - & - & + & - & + \\
\hline A2 & + & - & - & - & - & - & + & + & + \\
\hline A3 & + & - & - & - & - & - & - & - & + \\
\hline A4 & - & - & - & + & + & + & - & - & + \\
\hline B1a & + & $(+)$ & + & + & $(+)$ & - & + & $(+)$ & + \\
\hline $\mathrm{B} 1 \mathrm{~b}$ & $+^{a}$ & + & + & + & + & + & + & + & + \\
\hline
\end{tabular}

GFP-promoter reporters for A1a, B1a and A4 are given in Materials and Methods. Other reporters were as described. ${ }^{16,20}(+)$, weak expression.

${ }^{\mathrm{a}}$ In addition to previous expression results ${ }^{16}$ we found the B1b-promoter driven GFP expression also in the embryonic hypodermis. 


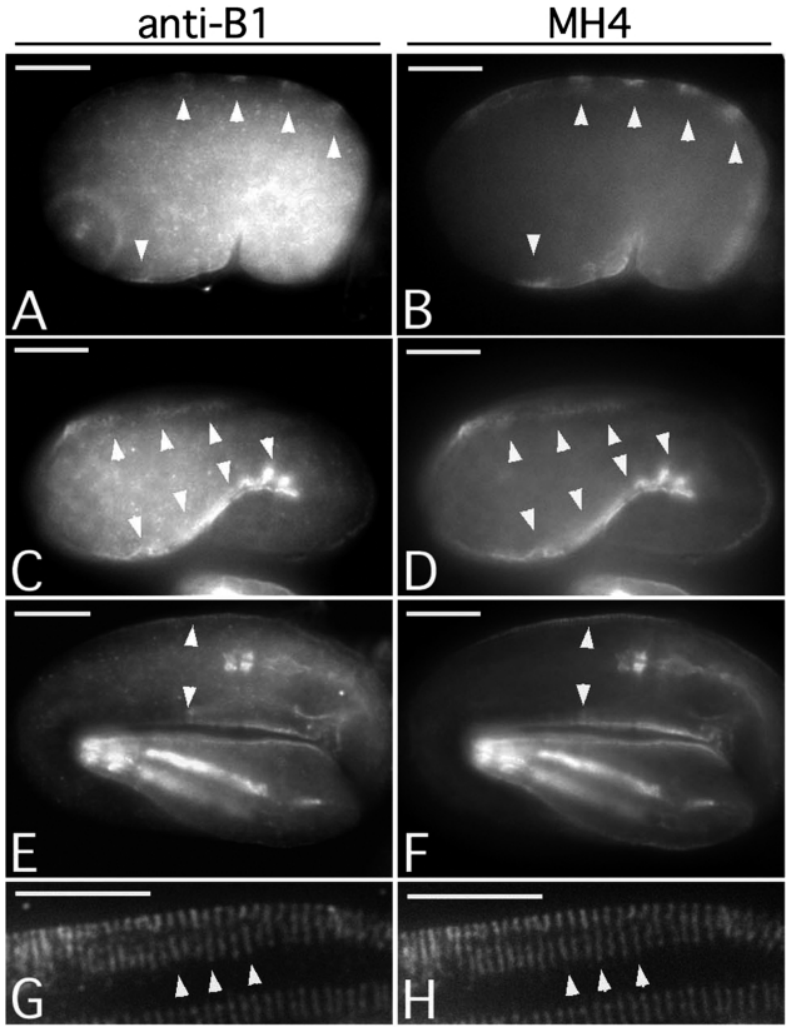

Figure 4. Colocalization of B1 and MH4 antigens in C. elegans embryo and larva. The left half of the Figure gives rabbit anti-B1 specific ${ }^{16}$ immunofluorescence of embryos (A, C and E) and the larva (G) that were double-stained with the murine monoclonal antibody MH4 that detects proteins A1 to A3 (right half of the Figure). The arrowheads highlight coexpression/coorganization of the B1 and the MH4 antigens in the dorsal and ventral hypodermis (except for the seam) of the comma (A and B), 1.5-fold (C and D) and 3-fold (E and F) stage embryos and the larva $(\mathrm{G}$ and $\mathrm{H})$.

\section{Equimolar mixtures of B1 and A1, A2 or A3 proteins yield heteropolymeric IF in vitro}

To test the polymerization properties of the recombinant proteins $\mathrm{B} 1 \mathrm{a}, \mathrm{A} 1 \mathrm{a}, \mathrm{A} 1 \mathrm{~b}, \mathrm{~A} 2$ and $\mathrm{A} 3$ in vitro, we dialyzed the proteins either alone or in all four possible equimolar B1a/A mixtures to remove the urea. Assembly products were monitored by electron microscopy after negative staining. While the individual proteins yielded only aggregates, the equimolar B1a/A1a, B1a/ $\mathrm{A} 1 \mathrm{~b}, \mathrm{~B} 1 \mathrm{a} / \mathrm{A} 2$ or B1a/A3 mixtures polymerized into long IF (Figure 6). Thus, proteins A1, A2 and $\mathrm{A} 3$ form an obligate heteropolymeric IF system with protein B1. We assume that this IF system includes protein A4, which is recognized strongly by the biotinylated B1 probe in the blot overlay (Figure 5). A direct assembly assay was not done because our recombinant A4 protein lacked the very $\mathrm{N}$-terminal end.

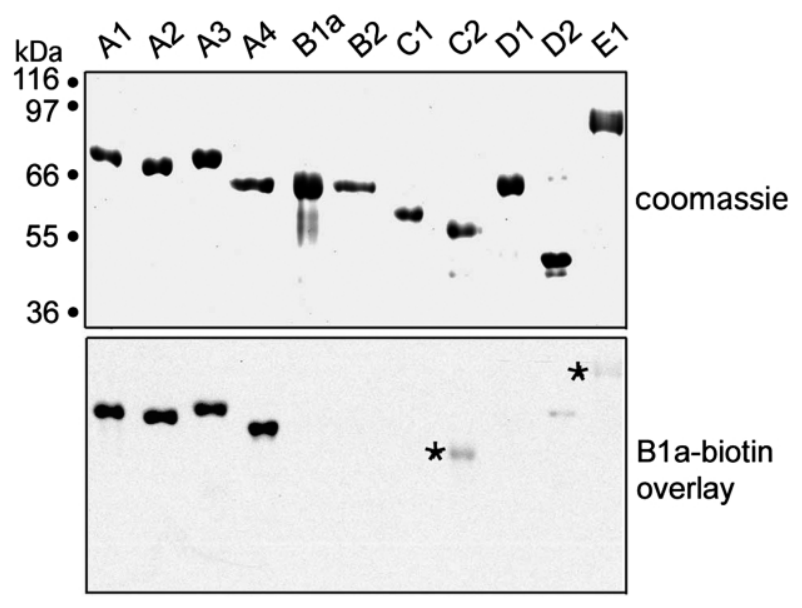

Figure 5. Blot overlay assays of biotin-labeled B1a protein on the 11 immobilized IF proteins. Equal amounts of purified recombinant proteins A1b, A2, A3, A4, B1a, B2, C1, C2, D1, D2 and E1 were separated by SDS/10\% PAGE and stained with Coomassie brilliant blue dye (upper panel) or transferred to nitrocellulose membranes. The lower panel shows the blot after incubation and staining with the B1a-biotin protein (marked on the right). The B1a-biotin probe, visualized by horse radish peroxidase-conjugated streptavidin, detects A1, A2, A3 and A4 proteins strongly and C2 and E1 very weakly (marked by asterisks $(*)$ ). All other IF proteins were negative. Approximate molecular mass standards (in $\mathrm{kDa})$ are given on the left of the upper panel.

\section{Calculation of interchain ionic interactions of individual A/B1 rod homo and heterodimers}

Before calculating the potential interchain ionic interactions, and hence the probable interacting pairs of chains in the two-stranded molecules, ${ }^{9,23}$ we tried to ascertain the coiled-coil regions in the proteins A1 to A4 and B1. As shown in Figure 1A, all five sequences are "classical" in the sense that they had easily recognisable 1A (35 residues), 1B (143 residues), 2A (19 residues) and 2B heptad-containing segments (121 residues), together with the intervening linkers. Segment 2B also had a stutter close to its mid-point, as is seen always in IF proteins. ${ }^{2-4}$ The interchain ionic interactions were determined for a total of 15 chain combinations involving the proteins A1 to A4 and B1 (Table 2). The B1 rod would, in order of ionic interaction score, significantly favour the B1/A2 $(+23), \mathrm{B} 1 /$ $\mathrm{A} 1 \quad(+20), \mathrm{B} 1 / \mathrm{A} 4 \quad(+20)$ and $\mathrm{B} 1 / \mathrm{A} 3 \quad(+18)$ heterodimerization over the formation of the $\mathrm{B} 1 / \mathrm{B} 1$ homodimer $(+12)$. In all cases the score is maximised for a parallel in-register chain arrangement. These results follow closely the heterotypic interactions of the protein B1 observed in the blot overlay and the in vitro polymerization experiments. Interestingly, however, the A chains seem able to form a heterodimer with another A chain (Table 2). 

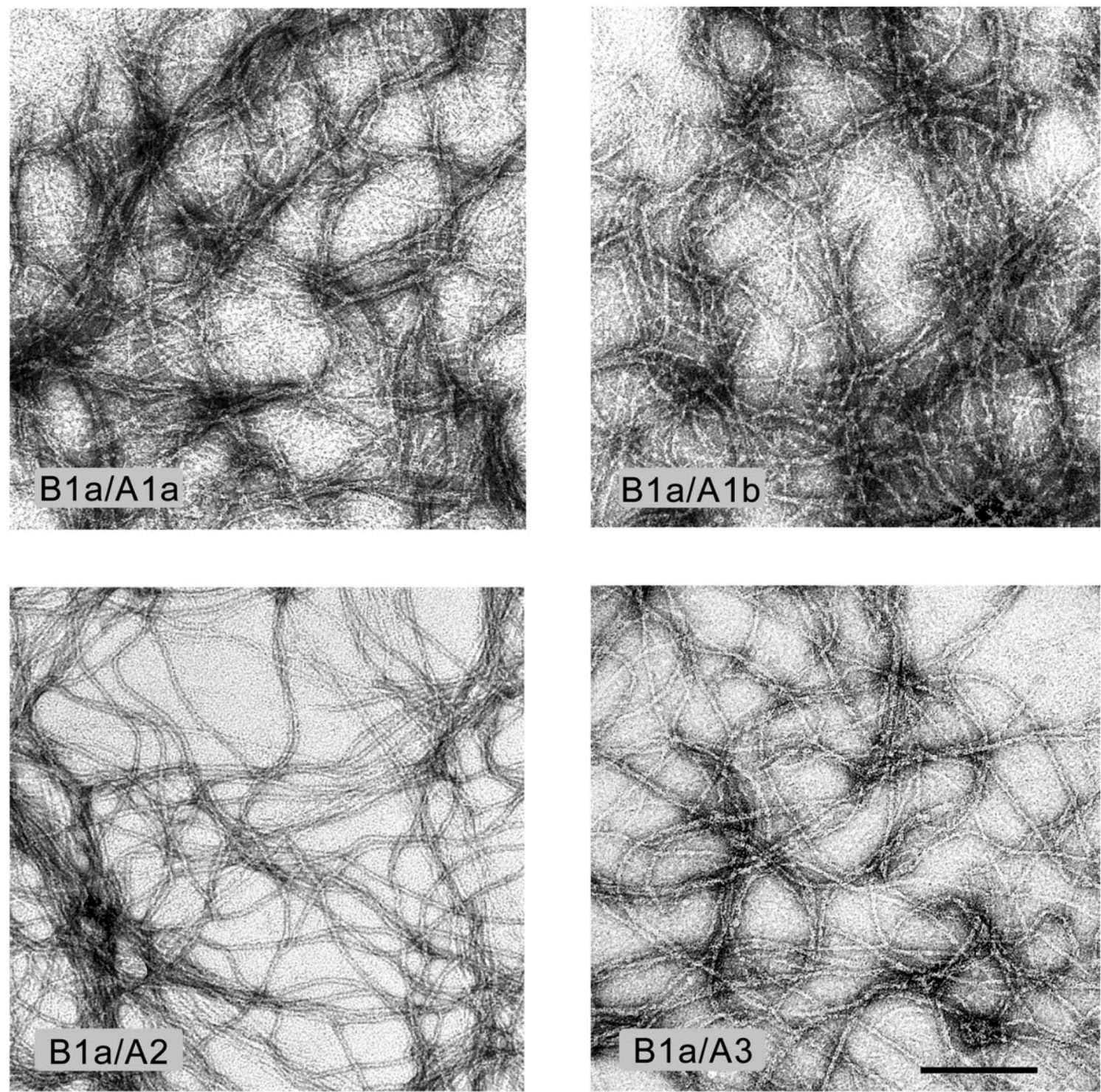

Figure 6. Electron micrographs of IF assembled in vitro from equal amounts of the recombinant proteins B1a/A1a, $\mathrm{B} 1 \mathrm{a} / \mathrm{A} 1 \mathrm{~b}, \mathrm{~B} 1 \mathrm{a} / \mathrm{A} 2$ and B1a/A3. The scale bar represents $0.2 \mu \mathrm{m}$.

Table 2. Interchain ionic interactions for parallel and in register arrangements of $\mathrm{A}$ and $\mathrm{B} 1$ protein rods

\begin{tabular}{lccccc}
\hline IF chain & A1 & A2 & A3 & A4 & B1 \\
\hline A1 & +24 & +25 & +21 & +24 & +20 \\
A2 & +25 & +22 & +19 & +24 & +23 \\
A3 & +21 & +19 & +16 & +16 & +18 \\
A4 & +24 & +24 & +16 & +24 & +20 \\
B1 & +20 & +23 & +18 & +20 & +12 \\
\hline
\end{tabular}

The numbers show potential ionic interactions calculated for charged residue pairs in positions $2 \mathrm{e}^{\prime}-1 \mathrm{~g}, 1 \mathrm{~g}^{\prime}-2 \mathrm{e}, 2 \mathrm{a}^{\prime}-1 \mathrm{~g}, 1 \mathrm{~g}^{\prime}-2 \mathrm{a}$, $1 \mathrm{e}^{\prime}-1 \mathrm{~d}$, and $1 \mathrm{~d}^{\prime}-1 \mathrm{e}$ of the two chains. Attractive interactions between oppositely charged residues were scored +1 and interactions between residues that are either both positively or both negatively charged were scored -1 . All other interactions were scored $0 ., 23$

\section{Copolymerization of $\mathrm{B} 1$ with $\mathrm{A} 2$ and $\mathrm{A} 3$ : the postembryonic RNAi phenotype of $B 1$ has the same hypodermal defects as the A2/A3 RNAi phenotypes}

The tissue-specific coexpression of $\mathrm{B} 1$ and the A proteins suggest that these proteins form heteropolymeric IF in vitro and in vivo. We have therefore explored some RNAi phenotypes. Earlier, using microinjection of the dsRNA into gonads, we found late embryonic lethality with multiple morphogenetic defects for B1 RNAi. ${ }^{16}$ However, when the B1 RNA was introduced by feeding, ${ }^{15,21}$ we observed a strong paralysis of the late larvae and adults resulting in $35 \%$ lethality $(n=368)$. The paralysed larvae exhibit detachment of the hypodermis from the cuticle (arrows in Figure 7A), displacement of body muscles (double arrow in Figure 7B) and uneven and sometimes cystic excretory canals (arrowheads in Figure 7C). These 
defects are the same as those reported for the A2/ A3 phenotypes obtained by microinjection. ${ }^{16}$ Thus, in line with the coexpression of $\mathrm{B} 1$ and $\mathrm{A} 2 / \mathrm{A} 3$ in the hypodermis (Table 1), all three RNAi phenotypes are closely related and indicate a defect in the hypodermal IF that most likely are built from the corresponding heteropolymers. Hypodermal IF are thought to participate in the transduction of force from the muscle to the cuticle. ${ }^{16-20}$
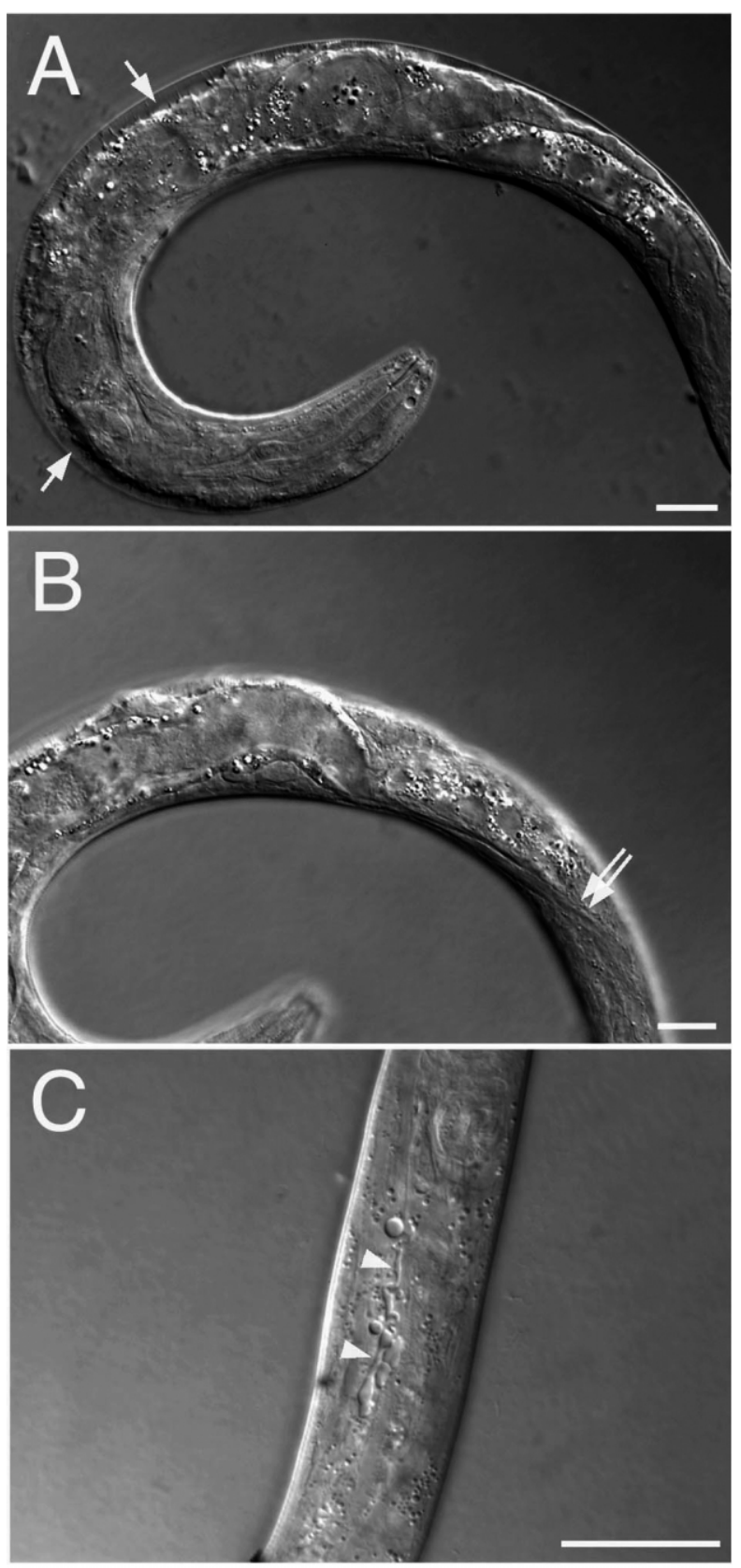

Figure 7. Postembryonic defects of larvae induced by B1 RNAi feeding. Nomarski views of larvae document detachment of the hypodermis from the cuticle (arrows in A), displaced body wall muscle (double arrow in B) and uneven and cystic excretory canals (arrowheads in C). Scale bars represent $25 \mu \mathrm{m}$.

\section{Copolymerization of B1 with A1: aberrant pharynx IF bundles containing $B 1, A 1$ and A1-GFP by B1 RNAi}

Worms expressing A1-GFP together with A1 and B1 in the pharynx were used in B1 RNAi feeding experiments (for details, see Materials and Methods). Figure 8 summarizes the striking structural defects in the pharyngeal marginal cells of live larvae visualized by the A1-GFP fluorescence. In the postembryonic $\mathrm{B} 1$ phenotype, defects ranged from abnormal aggregates observed mainly on the apical or basal side of the tonofilaments (marked by arrows in Figure $8 \mathrm{~A}$ and $\mathrm{C}$ ) to their nearly complete collapse and the loss of such filaments (Figure 8E). In about $60 \%$ of the larvae $(n=80)$ the posterior part of the pharynx was shifted from the central part to the periphery, indicating defects in the mechanical coupling of the organ with the surrounding hypodermal/ cuticle layer (arrow in Figure 8G).

\section{RNA interference of the IF genes A1, A2, A3 and $\mathrm{C} 2$ through feeding}

Since B1 dsRNA delivered by microinjection leads to a late embryonic RNAi phenotype, ${ }^{16}$ while feeding of the same RNA provided a larval/ adult phenotype (see above), we explored RNAi by the feeding method on the other IF genes (A1, A2 and A3) previously found to be essential in microinjection experiments. ${ }^{16}$

Using the RNAi feeding approach for A2 we observed a strong paralysis of the late larvae and adults resulting in about $30 \%$ lethality $(n=430)$. No phenotype was observed for the early larvae, which was in contrast to our results obtained by microinjection of the same dsRNA. ${ }^{16}$ Feeding with bacteria producing A1 or A3 dsRNA did not result in a recognizable phenotype. Interestingly, the same dsRNAs introduced by microinjection induced L1 arrest for A1 and embryonic and early larva lethality for A3. ${ }^{16}$ In RNAi feeding experiments using the C2 dsRNA, we observed adult lethality in about $3 \%$ of the progeny $(n=847)$. This was due to the rupture of vulva and/or anus (data not shown). In addition, about $10 \%$ of the C2 RNAi animals showed uncoordinated movement.

\section{Fluorescence recovery after photobleaching (FRAP) analyses of A1-GFP and B1-GFP containing tonofilaments of live marginal cells}

Recent FRAP studies using mammalian GFP-tagged IF proteins demonstrated that keratins K8-GFP and K18-GFP recover their fluorescence in the heteropolymeric keratin filaments approximately two hours after photobleaching. This process was about 20 times slower than that reported for homopolymeric vimentin in a similar experiment. ${ }^{24}$ We used a similar approach on the A1-GFP and B1-GFP-containing filament bundles in live marginal cells of the pharynx.

The photobleached filament bundles containing 


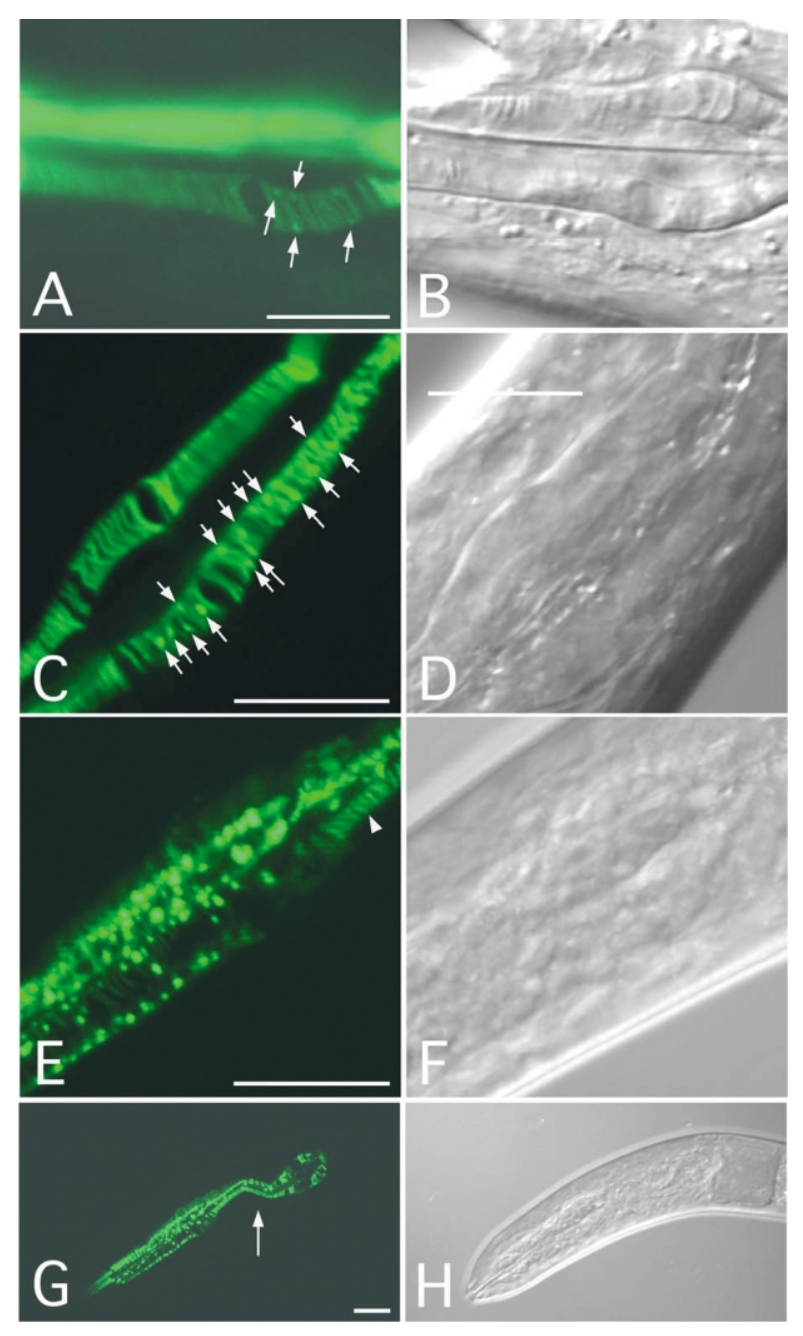

Figure 8. Aberrant A1-GFP-containing tonofilaments in marginal cells of live worms as result of B1 RNAi. Nomarski phase contrast monitoring (B, D, F and $\mathrm{H}$ ) was used to facilitate the identification of cells and tissues. Analysis of the B1 RNAi treatment using confocal fluorescence microscopy revealed different structural defects in the A1-GFP containing large filament bundles of the live pharyngeal marginal cells. These range from the abnormal aggregates observed mostly on the apical or basal side of the tonofilaments (marked by arrows in A and C) to the almost complete collapse and loss of the tonofilaments (E). These results reveal a requirement of protein B1 for the normal structure of the A1-GFP-containing tonofilaments in vivo. Moreover, in about $60 \%$ of the scored animals the posterior part of the pharynx was shifted from the central part to the periphery, indicating a defect in mechanical coupling of the pharynx to the surrounding hypodermis/cuticle layer (marked with the arrow in $\mathrm{G})$. Scale bars represent $10 \mu \mathrm{m}$.

A1-GFP in the marginal cell of the anaesthetised worm had not recovered their fluorescence by four hours after photobleaching (Figure 9; for details, see Materials and Methods). Similar results were obtained for the filament bundles containing B1a-GFP in worms expressing B1a under control of the B1b-specific promoter (for details, see Figure $1 \mathrm{~B}$, and Materials and Methods). The first signs of fluorescence recovery became visible at five hours
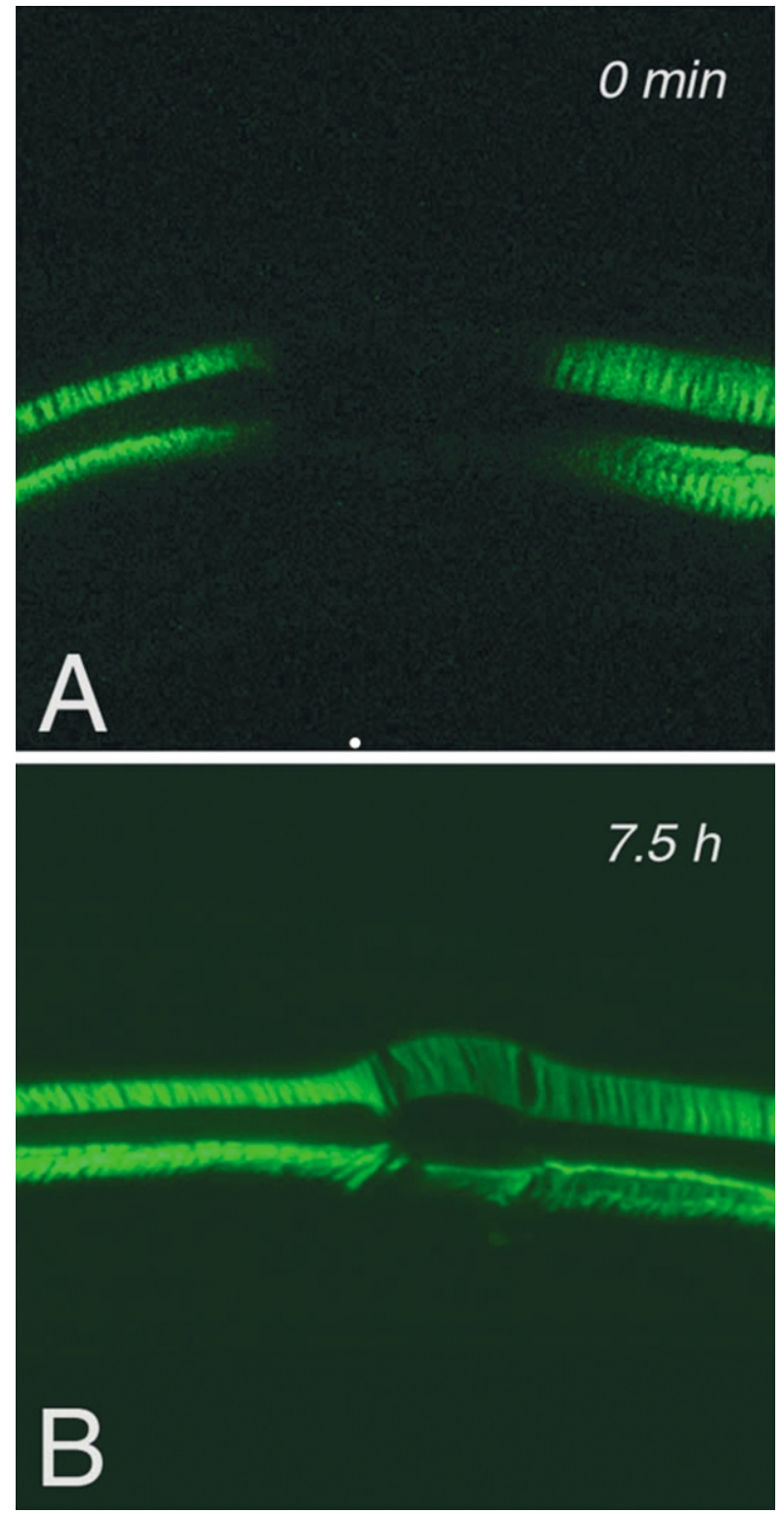

Figure 9. FRAP analysis of tonofilament bundles containing A1a-GFP in live marginal cell. The region around the pharyngeal metacorpus of the anesthesized transgenic Ala-GFP larva was photobleached (see Materials and Methods for details) and recovery of fluorescence was monitored every 30 minutes up to 7.5 hours. A and $\mathrm{B}$, The area of the A1a-GFP containing filament bundle 0 and 7.5 hours after photobleaching, respectively. As described in Results, the first signs of fluorescence recovery became visible five hours after bleaching and reached $35 \%$ at 2.5 hours later.

after bleaching, while the fluorescence quantification revealed $35 \%$ recovery at 7.5 hours after bleaching (Figure 9B). These results indicate that the turnover rate of B1-GFP and A1-GFP in the tonofibrils is similar and rather slow.

\section{Discussion}

C. elegans has 11 genes encoding cytoplasmic IF 
proteins. Using RNA interference with microinjection on all 11 genes, we identified four genes (A1, A2, A3, B1) as essential for nematode development. ${ }^{16}$ Here, we have defined the expression pattern of these genes during development using GFP-promoter reporters and have analyzed the in vitro assembly properties of the corresponding recombinant proteins. A strict coexpression pattern of B1 and the four members of the A subfamily (A1 to A4) is seen. When either one or both splice variants of the B1 gene occur, at least one of the members of the A family is expressed also. There is no tissue that expresses an A-type and does not express B1 simultaneously (Table 1). This relation holds for an unusual situation of the dauer larva. While the intestine lacks a B1/A pair during normal development, the intestine of the dauer larva shows B1/A4 expression.

This B1/A coexpression pattern fits the observation of an obligatory heteropolymeric IF assembly established with the recombinant proteins. Gel overlay assays performed with B1 on all 11 C. elegans IF proteins showed a strong binding only on A1 to A4 (Figure 5). Electron microscopy revealed that B1 as well as A1 to A3 dialyzed alone against filament buffer form only aggregates. In contrast equal molar mixtures of B1 with either A1, A2 or A3 provided normal IF (Figure 6). The obligate heteropolymeric B1/A assembly pathway is a keratin-related system but it differs from the mammalian keratins in that there is only one protein of one type which can assemble with four closely related proteins of the second type. Interestingly, a similar assembly system was documented in cephalochordates. Branchiostoma has a keratin I/keratin II system closely related to mammalian keratins that even allows the formation of chimeric IF from some Branchiostoma and vertebrate keratins. In this additional keratin-related system, a single Branchiostoma protein assembles only with three closely related IF proteins. For the latter system, the isolation of a polymerization-competent crosslinked heterodimer proved directly the presence of a hetero coiled coil. ${ }^{9}$ In the case of $C$. elegans $\mathrm{B} 1 / \mathrm{A}$, we tentatively assume the existence of a heterodimer, since the calculation of interchain ionic bonds for a parallel in-register arrangement is compatible with this view. Nevertheless, we note that the A proteins may have some tendency for homodimer formation (Table 2), which is not understood.

We do not know the assembly properties of the six remaining C. elegans IF proteins. Some of them could reflect proteins that are bound peripherally to IF but there must be an assembly system distinct from that of B1/A (Table 1). Although the intestine lacks the B1/A system, immunofluorescence microscopy of intestinal cells shows a wealth of IF proteins (A.K. \& K.W., unpublished results). We plan to study the assembly properties of some of the remaining IF proteins once we have learned more about the functional role of their genes using transgenic worms expressing negative dominant IF mutant proteins (see below).
Analysis of the RNAi-induced lethal phenotypes for $\mathrm{B} 1, \mathrm{~A} 1, \mathrm{~A} 2$ and $\mathrm{A} 3^{16}$ shows independent evidence for the existence of the B1/A obligate heteropolymer system in vivo. Using microinjection of B1 RNAi, we previously found a late embryonic lethality with hypodermal as well as general morphogenetic defects. Using the RNAi feeding protocol, we show now that the B1 phenotype arrests in the larva (for discussion, see below). This postembryonic B1 phenotype has the same hypodermal defects (Figure 7) as the A2 and A3 phenotypes: detachment of the hypodermis from the cuticle, displacement of the body muscle cells, uneven excretory canals and paralysis. ${ }^{16}$ The same hypodermal defects for B1, A2 and A3 fit the coexpression of the three proteins in the hypodermis (Table 1) and emphasize that the hemidesmosomeanchored IF, the so called fibrous organelles, ${ }^{17,18}$ participate in the transmission of force from the muscle to the cuticle. They are necessary to maintain the correct spatial relationship of hypodermis and muscle cells during development. The postembryonic B1 RNAi phenotype obtained by feeding shows additional defects that are particularly easy to monitor in transgenic worms expressing GFP-tagged A1 protein. In line with the coexpression of B1 and A1 in the pharyngeal marginal cells, striking structural defects of the tonofilament bundles are seen by green fluorescent protein (GFP) fluorescence. Moreover, the pharynx was shifted from the central part to the periphery (Figure 8). We therefore propose that in the late embryonic lethal B1 phenotype obtained by microinjection ${ }^{16}$ morphogenetic defects most likely arose from defects in embryonic hypodermis and pharynx.

Similar analyses of the B1a-GFP protein-containing tonofilaments in the pharynx of the RNAi arrested A1 larvae ${ }^{16}$ were not yet possible due to loss of the GFP-tagged protein expression in the F2 progeny (see Materials and Methods). Therefore, the physiological basis of the A1 RNAi phenotype is not entirely understood. Given the results of B1 RNAi in the pharynx (see above) one can speculate that the A1 larvae arrested because of feeding reduction due to pharynx defects.

Our original identification of four IF genes (A1, A2, A3 and B1) essential for nematode development was based on RNAi delivery by microinjection. ${ }^{16}$ Using delivery of the same dsRNA by bacterial feeding, we found that the late embryonic lethal phenotype of B1 obtained by microinjection is shifted to a later developmental stage and manifested itself as a larval/adult lethal phenotype. We took advantage of this shift to analyze the postembryonic B1 phenotype obtained by feeding, and documented the resulting hypodermal and pharynx defects in line with coexpression of B1 with either A2/A3 or A1. Because of the developmental shift of the B1 phenotype dependent on the RNAi delivery method, we analyzed the other three essential IF genes (A1, A2 and A3) by bacterial feeding with the same dsRNA probes used previously in the microinjection experiments. Our 
results show that feeding missed both the late embryonic/early larval lethality of A3 and the L1 larval arrest of A1 documented previously by microinjection. On the other hand, feeding clearly registered the larval lethality of $\mathrm{A} 2$, in agreement with earlier microinjection results. ${ }^{16}$ Screening of the results of the elegant high-throughput analysis published recently for nearly all C. elegans genes by RNAi feeding ${ }^{25}$ showed that this study registered only B1 and A2, with results similar to ours.

The differences in RNAi/phenotyping between the two delivery methods is not without precedence. Introducing the feeding protocol, Timmons et al. ${ }^{21}$ made the general prediction that this delivery method can be less effective than microinjection in establishing early developmental RNAi phenotypes, while it can be more effective than microinjection for late developmental stages. This is essentially what we observe with IF genes. Of the four late embryonic/larval RNAi phenotypes (A1, A2, A3 and B1) obtained by microinjection, ${ }^{16}$ delivery by feeding provides the A2 phenotype, shifts the late embryonic B1 phenotype to a late larval phenotype but missed the A1 and A3 phenotypes entirely. Thus, as predicted by Timmons et al., ${ }^{21}$ delivery by feeding is less effective than microinjection for early developmental RNAi phenotypes. On the other hand, C2 RNAi delivery by microinjection resulted only in a mild dumpy phenotype with reduced motion, ${ }^{16}$ while a much stronger adult phenotype, including defects of the vulva and the anus and an uncoordinated movement, occurs upon feeding (see Results and Kamath et al. ${ }^{25}$ ). This result is again in line with the predictions made by Timmons et al. ${ }^{21}$

Since both delivery methods show no effect on IF genes A4, B2, C1, D1, D2 or E1, ${ }^{16,25}$ the function of these six genes must be approached by a different strategy. One obvious way to try is to explore transgenic animals with negative dominant mutations, which can be modelled along the known point mutation in mammalian IF genes (see Introduction) or tentatively can be constructed to carry deletions of the highly conserved sequences at one or both ends of the rod domain. ${ }^{4,26,27}$

Here, for the first time, the properties of GFPtagged IF proteins have been analyzed in a living organism. We found that kinetics of fluorescence recovery after photobleaching (FRAP) of the A1-GFP or B1-GFP-containing tonofibrils in the marginal cells of the pharynx are similar and rather slow. In both cases the first signs of fluorescence recovery were visible approximately five hours after photobleaching. These results indicate that in the nematode cells there is an equilibrium between unpolymerized IF subunits and the polymerized IF of the tonofibrils. Moreover, a similar rate of fluorescence recovery for A1 and B1 proteins is in line with the obligatory heteropolymeric nature of the polymerised IF. Interestingly, the recovery times of the C. elegans pharynx IF are similar to those reported for mammalian keratin filaments in cultured cells, while the vimentin filaments of the same cells show a much faster recovery. ${ }^{24}$ Future experiments using GFP-tagged IF proteins should analyze their recovery rates in different subcellular regions or organs of $C$. elegans and try to determine the factors and/or proteins that influence IF tonofibril formation and turnover. As shown for the B1 RNAi phenotype of A1-GFP-expressing live worms (Figure 8), the RNAi approach may be a useful tool in this effort.

\section{Materials and Methods}

\section{Nucleic acid techniques}

C. elegans strain N2 Bristol was cultured and harvested using standard procedures. ${ }^{28}$ The full-length cDNAs of the A1b (F38B2.1a) and A3 (F52E10.5) IF proteins ${ }^{22}$ were amplified by PCR from the cDNA library as described. ${ }^{16}$ The following primers were used:

A1b sense 5'-CAATCAACATTTCAAAACATATGGA GATTACCAGAGAAAG-3', antisense 5'-GTTAATTGTT GGGAAGAAGCTTGATTAGGCAGTGCTC-3'; A3 sense 5'- CCATGGCCGATCCAGATTCCTACCGCAGCTC-3', antisense 5'-GATTTATGAAGTTGTAG-TCTGTTGGCTT TGGCG-3'.

The A1b and A3 PCR fragments were ligated to pCR2.1-TOPO vectors (Invitrogen, San Diego, CA, USA) and the inserts were sequenced completely (MWG-Biotech, Ebersberg, Germany). For expression of the fulllength proteins $\mathrm{A} 1 \mathrm{~b}$ and $\mathrm{A} 3$, restriction fragments from pCR2.1-TOPO vectors were cloned to pET23 vectors (Novagen, Madison, WI, USA).

The A1a-promoter/gene/gfp construct and the A4and B1a-promoter/gfp reporters were prepared from DNA fragments amplified by PCR on genomic DNA. ${ }^{16}$ The amplified A1a (4000 nt), A4 (2419 nt) and B1a (3186 nt) PCR products were ligated to pEGFP-N1 (A1a) or pEGFP-1 (B1a, A4) vectors (Clontech, Heidelberg, Germany) as HindIII/PstI, HindIII/Bam HI and XhoI/ Bam HI fragments, respectively. The following primers were used:

A1a sense 5'-GGAGGTGAGT-TGCGGAAGCTTTGC CTTTGTATTTCG-3' , antisense 5'-CTGATTAGGCAGTG CTCTGCAGTT-GGATGTGGGTAGC-3'; A4 sense $5^{\prime}$ CGTAGTTTATCCCCAAGCTTATTGTCTACATAGATC-3', antisense 5'-CGGTATTCGCTCTCCGACGGATCCTACA AACATGGAAAC-3'; B1a-promoter sense 5'-CTATATC CTTTCCTCTGAAAATACTCGAGAATACCAGGAGCA TTTCTTG-3' , antisense 5'-GGTGCCTGTGGCGCTGATT CAGGATCCATTTCTGATGTGTTTTAGCTTG-3'.

The B1b-promoter/B1a-cDNA/gfp construct was prepared by cloning the Bam HI-digested coding region of the B1a cDNA (F10C1.2a) into the Bam HI-digested B1bpromoter/gfp reporter (for details, see Karabinos et al ${ }^{16}$ ). Either microinjection or ballistic transformation of the A4-promoter-, B1a-promoter- and B1b-promoter/ B1acDNA-gfp plasmids was used to obtain unintegrated transgenic lines. ${ }^{16}$ These lines were used for the characterization of GFP expression and the FRAP analyses. Because of the loss of B1a-GFP protein expression in the F2 progeny, only F1 transgenic arrays could be used for the FRAP analysis.

A vector for the transformation of $C$. elegans by particle bombardment using the unc-119 rescue approach was created by transferring the wild-type unc-119 gene of plasmid pMM016 as a HindIII/XbaI restriction 
fragment into the NheI/HindIII cut vector pEGFP-N1 (Clontech Laboratories, Palo Alto, CA, USA) resulting in pEGFP-N1-unc-119. The C. elegans intermediate filament A1a-promoter/gene/gfp gene fusion from the pEGFP-1 plasmid (see above) was inserted as a HindIII/Not I restriction fragment. The construct was used to transform the C. elegans strain DP38 unc-119(ed3) III by particle bombardment as described by Praitis et al..$^{29}$ The resulting C. elegans strain EC668 showed unc-119 rescue and A1-GFP expression, and contained the transgene as an extrachromosomal array. For the RNAi feeding experiments, the coding cDNAs for A1, A2, A3, B1 and C2 $2^{16}$ were ligated between the phage $\mathrm{T} 7$ promoters of the L4440 feeding vector. ${ }^{15}$

\section{Protein and antibody techniques}

Cloning, expression and purification of the recombinant IF proteins A1a, A2 and B1a have been described. ${ }^{16}$ For expression of full-length proteins $\mathrm{A} 1 \mathrm{~b}$ and $\mathrm{A} 3$, the Escherichia coli strain BL21(DE3)pLysS (Novagen) was transformed with the A1b and A3 pET23 plasmids (see above). Recombinant proteins A1b and A3, highly enriched in inclusion body preparations, were purified in urea by ion-exchange chromatography as described. ${ }^{16}$ Biotinylation of recombinant protein $\mathrm{B} 1 \mathrm{a}$ and the overlay assay were essentially as described. ${ }^{9,30}$ After washing, the membrane was treated with horse-radish peroxidaseconjugated streptavidin (Pierce, Rockford, IL, USA) and developed using the ECL chemiluminiscence kit (Amersham Pharmacia, Uppsala, Sweden). For in vitro assembly, aliquots of recombinant proteins either alone or as stoichiometric mixtures were dialyzed at room temperature for 20 hours on dialysis filters against filament buffer containing $1 \mathrm{mM}$ 2-mercaptoethanol. The following filament buffers were used: for B1a/A1a (each $0.3 \mathrm{mg} / \mathrm{ml}) 5 \mathrm{mM}$ Tris $-\mathrm{HCl}(\mathrm{pH} 7.2)$, containing $15 \mathrm{mM}$ $\mathrm{NaCl}$; for B1a/A1b (each $0.4 \mathrm{mg} / \mathrm{ml}$ ), B1a/A2 (each $0.6 \mathrm{mg} / \mathrm{ml}$ ) and B1a/A3 (each $0.8 \mathrm{mg} / \mathrm{ml}) 10 \mathrm{mM}$ Tris$\mathrm{HCl}$ ( $\mathrm{pH}$ 7.2). Negative staining and electron microscopy were as described. ${ }^{31}$

Indirect immunofluorescence microscopy of $C$. elegans embryos and larvae was performed as described. ${ }^{16}$ Confocal light microscopy of C. elegans larvae and adults was performed using the Zeiss confocal laser scanning microscope LSM 510 with software version 2.02. The antigen affinity-purified rabbit B1 antibody ${ }^{16}$ was diluted 1:2 and the murine monoclonal antibody MH4 (Developmental Studies Hybridoma Bank, University Iowa, USA) was used as 1:25 dilution of a hybridoma supernatant.

\section{RNA interference mediated by feeding}

RNAi feeding experiments were performed essentially according to Fraser et al. ${ }^{15}$ but with the following modifications. The $5 \mathrm{~cm}$ NGM plates containing carbenicillin $(25 \mu \mathrm{g} / \mathrm{ml})$ and $1 \mathrm{mM}$ IPTG were inoculated with $5 \mu \mathrm{l}$ of the overnight A1-, A2-, A3-, B1- or C2-cDNA/L4440transformed HT115(DE3) bacterial culture and left for six hours at room temperature. The L3-L4 stage worms (F0) were washed with M9 medium and placed individually onto the feeding plates and incubated for 48 hours at temperatures between $20^{\circ} \mathrm{C}$ and $23^{\circ} \mathrm{C}$. The F0 worms were removed from the plates and their progeny (F1) was scored for abnormalities by Nomarski and fluorescence microscopy.

\section{Fluorescence recovery after photobleaching (FRAP) analyses}

FRAP experiments were made using the Zeiss confocal laser scanning microscope LSM 510 with software version 2.02. Worms expressing A1a-GFP and B1a-GFP were anaesthetised for 20 mintes by the method of Kirby et al. ${ }^{32}$ in $0.1 \%$ tricaine, $0.01 \%$ tetramisole in water. The region around the pharyngeal metacorpus of live GFP-expressing nematodes was photobleached with a laser wavelength of $488 \mathrm{~nm}$ (serial laser scanning with manually adjusted $z$-coordinates). The bleached animals were put on to OP50 E. coli plates and recovery of the fluorescence was monitored at 30 minute intervals for up to 7.5 hours using fluorescence microscopy. The animals resumed a normal mode of locomotion three hours after bleaching. First signs of fluorescence recovery became visible five hours after bleaching. Fluorescence quantification was done 7.5 hours after bleaching by laser scanning microscopy. Average background fluorescence was subtracted. The analysis of the lateral average fluorescence of the bleached and the nonbleached areas indicated a fluorescence recovery of 35\% 7.5 hours after bleaching and 4.5 hours after the recovery of normal locomotion.

\section{Acknowledgements}

We thank Uwe Plessmann and Wolfgang BerningKoch for expert technical assistance. This work was supported, in part, by the Deutsche Forschungsgemeinschaft grant SCHU 1033/3-4 to E.S.

\section{References}

1. Hesse, M., Magin, T. M. \& Weber, K. (2001). Genes for intermediate filament proteins and the draft sequence of the human genome: novel keratin genes and a surprisingly high number of pseudogenes related to keratin genes 8 and 18. J. Cell Sci. 4, 2569-2575.

2. Fuchs, E. \& Weber, K. (1994). Intermediate filaments: structure, dynamics, function and disease. Аnпи. Rev. Biochem. 63, 345-382.

3. Parry, D. A. D. \& Steinert, P. M. (1995). Intermediate Filament Structure, Springer, New York.

4. Herrmann, H., Hesse, M., Reichenzeller, M., Aebi, U. \& Magin, T. M. (2003). Functional complexity of intermediate filament cytoskeletons: from structure to assembly to gene ablation. Int. Rev. Cytol. 83, 83-175.

5. Irvine, A. D. \& McLean, W. H. (1999). Human keratin diseases: the increasing spectrum of disease and subtlety of the phenotype-genotype correlation. $\mathrm{Br}$. J. Dermatol. 140, 815-828.

6. Goldfarb, L. G., Park, K. Y., Cervenakova, L., Gorokhova, S., Lee, H. S., Vasconcelos, O. et al. (1998). Missense mutations in desmin associated with familial cardiac and skeletal myopathy. Nature Genet. 19, 402-403.

7. Brenner, M., Johnson, A. B., Boespflug-Tanguy, O., Rodriguez, D., Goldman, J. E. \& Messing, A. (2001). Mutations in GFAP, encoding glial fibrillary acidic 
protein, are associated with Alexander disease. Nature Genet. 27, 117-120.

8. Goldman, R. D. (2001). Worms reveal essential functions for intermediate filaments. Proc. Natl Acad. Sci. USA, 98, 7659-7661.

9. Karabinos, A., Schünemann, J., Parry, D. A. D. \& Weber, K. (2002). Tissue-specific coexpression and in vitro heteropolymer formation of the two small Branchiostoma intermediate filament proteins A3 and B2. J. Mol. Biol. 316, 127-137.

10. Wang, J., Karabinos, A., Schünemann, J., Riemer, D. \& Weber, K. (2000). The epidermal intermediate filament proteins of tunicates are distant keratins; a polymerisation-competent hetero coiled coil of the Styela D protein and Xenopus keratin 8. Eur. J. Cell Biol. 79, 478-487.

11. Wang, J., Karabinos, A., Zimek, A., Meyer, M., Riemer, D., Hudson, C. et al. (2002). Cytoplasmic intermediate filament protein expression in tunicate development; a specific marker for the test cells. Eur. I. Cell Biol. 81, 302-311.27.

12. Weber, K., Plessmann, U. \& Ulrich, W. (1989). Cytoplasmic intermediate filament proteins of invertebrates are closer to nuclear lamins than are vertebrate intermediate filament proteins; sequence characterization of two muscle proteins of a nematode. EMBO J. 8, 3221-3227.

13. Erber, A., Riemer, D., Bovenschulte, M. \& Weber, K. (1998). Molecular phylogeny of metazoan intermediate filament proteins. J. Mol. Evol. 47, 751-762.

14. Liu, J., Ben-Shahar, T. R., Riemer, D., Treinin, M., Spann, P., Weber, K. et al. (2000). Essential roles for Caenorhabditis elegans lamin gene in nuclear organization, cell cycle progression, and spatial organization of nuclear pore complexes. Mol. Biol. Cell, 11, 3937-3947.

15. Fraser, A. G., Kamath, R. S., Zipperlen, P., MartinezCampos, M., Sohrmann, M. \& Ahringer, J. (2000). Functional genomic analysis of C. elegans chromosome I by systematic RNA interference. Nature, 408, 325-330.

16. Karabinos, A., Schmidt, H., Harborth, J., Schnabel, R. \& Weber, K. (2001). Essential roles for four cytoplasmic intermediate filament proteins in Caenorhabditis elegans development. Proc. Natl Acad. Sci. USA, 98, 7863-7868.

17. Francis, R. \& Waterston, R. H. (1991). Muscle cell attachement in Caenorhabditis elegans. J. Cell Biol. 114, 465-479.

18. Hresko, M. C., Williams, B. D. \& Waterston, R. H. (1994). Assembly of body wall muscle and muscle cell attachment structures in Caenorhabditis elegans. J. Cell Biol. 124, 491-506.

19. Hresko, M. C., Schriefer, L. A., Shrimankar, P. \& Waterston, R. H. (1999). Myotactin, a novel hypo- dermal protein involved in muscle-cell adhesion in Caenorhabditis elegans. J. Cell Biol. 146, 659-672.

20. Karabinos, A., Schulze, E., Klisch, T., Wang, J. \& Weber, K. (2002). Expression profiles of the essential intermediate filament (IF) protein A2 and the IF protein C2 in the nematode Caenorhabditis elegans. Mech. Dev. 117, 311-314.

21. Timmons, L., Court, D. L. \& Fire, A. (2001). Ingestion of bacterially expressed dsRNAs can produce specific and potent genetic interference in Caenorhabditis elegans. Gene, 263, 103-112.

22. Dodemont, H., Riemer, D., Ledger, N. \& Weber, K. (1994). Eight genes and alternative RNA processing pathways generate an unexpectedly large diversity of cytoplasmic intermediate filament proteins in the nematode Caenorhabditis elegans. EMBO J. 13, 2625-2638.

23. Citi, S., D'Atri, F. \& Parry, D. A. D. (2000). Human and Xenopus cingulin a modular organization of the coiled-coil rod domain: predictions for intra- and intermolecular assembly. J. Struct. Biol. 131, 135-145.

24. Yoon, K. H., Yoon, M., Moir, R. D., Khuon, S., Flitney, F. W. \& Goldman, R. D. (2001). Insights into the dynamic properties of keratin intermediate filaments in living epithelial cells. J. Cell Biol. 153, 503-516.

25. Kamath, R. S., Fraser, A. G., Dong, Y., Poulin, G., Durbin, R., Gotta, M. et al. (2003). Systematic functional analysis of the Caenorhabditis elegans genome using RNAi. Nature, 421, 231-237.

26. Herrmann, H. \& Aebi, U. (2000). Intermediate filaments and their associates: multi-talented structural elements specifying cytoarchitecture and cytodynamics. Curr. Opin. Cell Biol. 12, 79-90.

27. Strelkov, S. V., Herrmann, H. \& Aebi, U. (2003). Molecular architecture of intermediate filaments. BioEssays, 25, 243-251.

28. Sulston, J. E. \& Hodgkin, J. (1988). Methods. In The Nematode Caenorhabditis elegans (Wood, W. B., ed.), pp. 587-606, Cold Spring Harbor Laboratory Press, Cold Spring Harbor, NY.

29. Praitis, V., Casey, E., Collar, D. \& Austin, J. (2001). Creation of low-copy integrated transgenic lines in Caenorhabditis elegans. Genetics, 157, 1217-1226.

30. Hatzfeld, M., Maier, G. \& Franke, W. W. (1987). Cytokeratin domains involved in heterotypic complex formation determined by in vitro binding assays. J. Mol. Biol. 197, 237-255.

31. Karabinos, A., Schünemann, J., Meyer, M., Aebi, U. \& Weber, K. (2003). The single nuclear lamin of Caenorhabditis elegans forms in vitro stable intermediate filaments and paracrystals with a reduced axial periodicity. J. Mol. Biol. 325, 241-247.

32. Kirby, C., Kusch, M. \& Kemphues, K. (1990). Specification of male development in Caenorhabditis elegans: the fem genes. Dev. Biol. 105, 234-239.

Edited by M. Yaniv 